\title{
Delegating Pricing Power to Customers: Pay What You Want or Name Your Own Price?*
}

\author{
Florentin Krämer ${ }^{\dagger}$ Klaus M. Schmidt Martin Spann $^{\ddagger}$ Lucas Stich
}

May 7, 2015

\begin{abstract}
Pay What You Want (PWYW) and Name Your Own Price (NYOP) are customerdriven pricing mechanisms that give customers (some) pricing power. Both have been used in service industries with high fixed capacity costs in order to appeal to additional customers by reducing prices without setting a reference price. In this experimental study we compare the functioning and the performance of these two pricing mechanisms. We show that both mechanisms can be successfully used to endogenously price discriminate. PWYW can be very successful if there is an additional promotional benefit to using PWYW and if marginal costs are not too high. PWYW is a very aggressive competitive strategy that achieves almost full market penetration. NYOP is a less aggressive strategy that can also be used if marginal costs are high. It reduces price competition and segments the market. Low valuation customers are more likely to use NYOP while high valuation customers prefer a posted price seller.
\end{abstract}

JEL Classification Numbers: D03, D21, D22, D40, L11, M31

Keywords: Customer-driven pricing mechanisms; Pay What You Want; Name Your Own Price; Competitive Strategies; Marketing; Laboratory Experiment.

*Financial support by Deutsche Forschungsgemeinschaft through grants SCHM 1196/5-1 \& SP 702/2-1 and the Excellence Initiative of the German government through MELESSA is gratefully acknowledged. We would like to thank seminar audiences at Munich and at the International Meeting on Experimental and Behavioral Sciences (IMEBESS) in Toulouse for helpful comments and suggestions.

${ }^{\dagger}$ Department of Economics, University of Munich, D-80539 Munich, email: florentin.kraemer@econ.lmu.de

${ }^{\ddagger}$ Department of Economics, University of Munich, D-80539 Munich, email: klaus.schmidt@lmu.de

$\S$ Munich School of Management, University of Munich, D-80539 Munich, email: spann@spann.de

ॠMunich School of Management, University of Munich, D-80539 Munich, email: stich@lmu.de. Authors contributed equally and are listed in alphabetical order. 


\section{Introduction}

In many service industries such as hotels, airlines or entertainment firms have large fixed costs for capacity but face widely fluctuating demand. Sophisticated methods of price discrimination such as yield management have been developed to use capacity optimally by setting (often vastly) different prices in periods with high demand and in periods when demand is low (Weatherford and Bodily, 1992). However, offering low prices in reaction to off-peak demand bears the risk that consumers' reference prices are affected, which may significantly reduce their willingness-to-pay in periods with regular and peak demand (Kalyanaram and Winer, 1995) 11

A potential solution to this problem are so called customer-driven pricing mechanisms that price discriminate without setting a reference point by delegating the pricing decision to customers: Sellers using "Pay What You Want" (PWYW) ask consumers to pay any price they like, including zero (Schmidt et al., 2014). Sellers using "Name Your Own Price" (NYOP) ask consumers to submit a bid against a threshold that is set by the seller but unknown to buyers. A transaction takes place only if the offered price exceeds this threshold (Spann and Tellis, 2006). NYOP has been invented by Priceline, an online travel intermediary selling flights, hotel rooms, rental cars and vacation packages in the U.S. (Anderson, 2009; Dolan and Moon, 2000) ? $^{2}$ PWYW has been applied mainly in service industries such as hotels, restaurants or museums (Kim et al. 2009) 3 These pricing mechanisms achieve endogenous price discrimination because different customers pay different prices depending on their valuations, their conception of fairness, their beliefs about acceptable bids, or their degree of risk aversion.

Customer-driven pricing mechanisms offer additional benefits compared to traditional posted prices. Their participatory and innovative nature appeals to many consumers and often initiates word-of-mouth recommendations and favorable press coverage Hinz and Spann, 2008; Kim et al. 2009). Thus, they can be a powerful tool to promote a product to a wider

\footnotetext{
${ }^{1}$ For example, hotels in New York City experience low booking rates especially in January and February and apparently try to increase capacity utilization by lowering prices. See, e.g., http://www.nycedc.com/economicdata/travel-and-tourism. However, prices are not decreased enough to make full use of capacity, which may be explained by concerns about reference price effects.

${ }^{2}$ Priceline's business model has been very successful, with a current market cap of $\$ 65.5$ bn and gross profit of $\$ 7.6$ bn (http://finance.yahoo.com/q/ks?s=PCLN+Key+Statistics). Other current examples of NYOP sellers include the Danish website prisminister.dk, or eBay sellers selling via eBay's Best Offer option.

${ }^{3}$ See for example http://www.bbc.com/travel/feature/20140730-pay-what-you-want-at-a-paris-hotel, http://www.freetoursbyfoot.com/new-york-tours/, http://ibispaywhatyouwant.co.in/.
} 
audience. For instance, two German zoos recently used PWYW to attract customers in wintertime. Even though customers pay on average significantly less than the regular price, there can be so many additional customers that the combined effect on revenues is positive. Furthermore, customers may tell their friends and family that a visit to the zoo is fun, thereby increasing demand in non-PWYW periods. The positive effects of generating additional demand are particularly powerful if the firm has a strong social media position with many fans and followers.

There are many examples showing that delegating pricing power to consumers can be a viable and successful strategy. However, the driving forces of buyer and seller behavior (either facing or employing such mechanisms) are not yet fully understood. This paper contributes to the understanding of customer-driven pricing mechanisms by addressing the following questions under tightly controlled conditions: Under which circumstances should a firm delegate all pricing power to customers (PWYW) and when should it keep some control by setting a secret reserve price (NYOP)? How do additional benefits of customer-driven pricing mechanisms (such as media buzz and word-of-mouth advertising) affect this decision? How do buyer characteristics such as valuations, risk attitudes and social preferences affect the prices that buyers pay voluntarily? How do seller characteristics such as costs and market power affect the profitability of customer-driven pricing mechanisms? And finally, how successful are PWYW and NYOP as competitive strategies if there is a competing posted-price seller on the market? We conduct a series of controlled laboratory experiments to investigate these questions and to evaluate the strengths and weaknesses of PWYW and NYOP as an alternative to posted prices. Our design enables us to identify the causal impact of these factors on profitability and market penetration.

We find that both PWYW and NYOP are effective in achieving endogenous price discrimination. PWYW yields lower profit margins than NYOP, but it is extremely successful in achieving high market penetration. If a seller offers PWYW then almost all buyers shop with this seller. If a seller offers NYOP while another seller offers the same good at a posted price, then the NYOP seller captures only about 65 percent of the market. Sellers understand the merits and dangers of PWYW and use it only if their costs are low and if there is an additional benefit to using PWYW (e.g., more press coverage or word-of-mouth recommendations). If used appropriately, PWYW can be more profitable than NYOP despite its lower profit margin because it achieves (almost) full market penetration. Furthermore, our results show that PWYW successfully appeals to social preferences. Consumers pay more the more fair-minded 
they are and the larger their valuation and the larger the cost of the seller. In contrast, the prices offered to NYOP sellers are not affected by social preferences. With NYOP, consumers face strategic uncertainty because they do not know the threshold set by the seller. They pay more than the seller's marginal cost to make sure that they receive the good. However, if their valuation is high they prefer to shop with the posted price seller where they can get the good with certainty.

Our results suggest that PWYW is a very aggressive strategy that drives competing posted price sellers out of the market. If there is an additional benefit and if marginal costs are not too high, then PWYW is more successful than NYOP because it captures a larger fraction of the market. In contrast, NYOP can also be used for goods with high marginal costs because the seller can protect himself against selling his good below cost by setting an appropriate reserve price. NYOP is a much less aggressive strategy than PWYW. It relaxes price competition (in fact, with NYOP no price is quoted) and leaves a significant share of the market to the competing posted-price seller. It is particularly appealing to low valuation customers who do not lose much if their bid is unsuccessful and for whom the price offered by a posted-price seller is too high. High valuation customers, on the other hand, prefer to buy from the posted price seller in order to avoid the risk that their bid is unsuccessful.

So far the literature on customer-driven pricing mechanisms has dealt with PWYW and NYOP separately. There are many case studies and field experiments on PWYW in specific industries. These include the music industry, $!^{4}$ zoos and museums $5^{5}$ restaurants and wine bars,$^{6}$ online content $7^{7}$ hotel ${ }^{8}$ and travel agencies $9^{9}$ souvenir photos in an amusement park ${ }^{10}$ or the Google service Google Answers ${ }^{11}$ These studies are highly instructive but they cannot identify the causal effects driving behavior in these markets.

There are a few laboratory studies that allow for more control of the environment. For

\footnotetext{
${ }^{4}$ PWYW has been used by the bands "Radiohead", "Nine Inch Nails", and "Moby" (Johnson and Cui, 2013) as well as by the online music label "Magnatune" (Regner and Barria, 2009).

${ }^{5}$ The zoos of Münster and Augsburg in Germany used PWYW in the winter of $2014 / 15$. This pricing model is also employed by many museums such as the Metropolitan Museum of Art in New York or the Museum König in Bonn, Germany.

${ }^{6}$ Examples include the restaurant "Kish" in Frankfurt, Germany (Kim et al., 2010), or "Der Wiener Deewan" in Vienna, Austria, and wine bars like "Weinerei" in Berlin, Germany.

${ }^{7}$ For example Wikipedia and Humble Bundle.

${ }^{8}$ See Gautier and van der Klaauw (2012) on a promotional campaign of hotels in Belgium and the Netherlands using PWYW.

${ }^{9}$ See León et al. (2012) on the company Atrápalo SL in Spain.

${ }^{10}$ See Gneezy et al. (2010).

${ }^{11}$ See $\overline{\text { Regner }}(2014)$.
} 
example, Mak et al. (2015) use a laboratory experiment to study how subjects can coordinate their behavior to make PWYW viable even if they are not motivated by social preferences. Schmidt et al. (2014) also use a laboratory experiment on PWYW markets to identify the causal effects that determine voluntary payments both in monopolistic and competitive markets. However, they focus on an environment in which (a few) buyers and a seller interact repeatedly, so that buyers have an incentive to keep the seller in business. This is an important concern for neighborhood restaurants and other local service industries with a stable customer base. In contrast, the present paper is concerned with industries in which firms face a large and anonymous customer base with many customers dropping in only once. In the experiments there is pure one-shot interaction between buyers and sellers which makes it much more difficult for PWYW to be viable. Another important innovation of the current paper is the introduction of additional benefits that accrue to sellers employing a customer-driven pricing mechanism. Finally, we do not only analyze PWYW but are, to the best of our knowledge, the first to compare and contrast how PWYW and NYOP perform relative to each other as a function of the environment.

Research on Name You Own Price has been strongly influenced by the business model of Priceline. The majority of the related research focuses on NYOP sellers' design decisions such as repeated bidding and bidding fees (Fay, 2004; Spann et al., 2010), joint bidding for multiple items (Amaldoss and Jain, 2008), bid/price elicitation (Chernev, 2003; Spann et al., 2012) and haggling (Terwiesch et al., 2005). In addition, there are some papers studying the effects of competition on the profitability of a NYOP channel (Fay, 2009; Shapiro, 2011) and reasons for the existence of the channel itself (Wang et al., 2009).

Another stream of research on NYOP is concerned with buyers' bidding behavior and related papers analyze the role of bidders' emotions (Ding et al. 2005), expectations about changes in sellers' threshold level (Fay and Laran, 2009; Fay and Lee, 2015), information diffusion about seller's threshold level (Hinz and Spann, 2008) and adaptability of the threshold level (Hinz et al., 2011) on buyers' bidding behavior. Further, empirical research using historic NYOP bidding data analyzes bidder characteristics such as frictional costs (Hann and Terwiesch, 2003, Terwiesch et al., 2005), rationality (Spann and Tellis, 2006), risk aversion (Abbas and Hann, 2010) or willingness to pay (Spann et al., 2004).

The remainder of this paper is organized as follows: in Section 2, we describe the experimental design and procedures in detail. Section 3 provides theoretical predictions for seller and buyer behavior in PWYW and NYOP. The results are discussed in Section 
4. Section 5 concludes the paper with a general discussion. All formal proofs and the experimental instructions can be found in the Appendix.

\section{Experimental Design \& Procedures}

\subsection{General Setup}

The aim of this study is to better understand under what circumstances sellers choose customer-driven pricing mechanisms and why this may be profitable. We start out with two treatments in which two sellers compete for customers. The first seller is constrained to quoting a posted price. The second seller can decide between quoting a posted price or delegating the pricing decision to customers. In treatment NCFlex (Name Your Own Price, Competition, Flexible role) the flexible seller can opt for the Name Your Own Price mechanism instead of a posted price, in treatment PCFlex (Pay What You Want, Competition, Flexible role) he can opt for the Pay What You Want mechanism. These treatments offer first insights under what conditions actual sellers find different customer-driven pricing mechanisms attractive.

In a second step we want to better understand the effects of customer-driven pricing mechanisms under competitive conditions. If sellers can choose whether or not to use these mechanisms we have a potential selection bias: Only sellers who expect customer-driven pricing mechanisms to be profitable will select them. Therefore we do not observe how the mechanisms work in situations where sellers expect them to be unprofitable. Furthermore, if sellers choose a customer-driven pricing mechanism, buyers could interpret this as a signal about some characteristics of the seller. To exclude these effects we conducted two additional treatments in which again two sellers compete: The first seller is constrained to quote a posted price and the second seller is constrained to either using Name Your Own Price (in treatment NCFix) or to using Pay What You Want (in treatment PCFix). In a third step we want to analyze how competition with the posted-price seller affects the prices that buyers are offering to pay. Thus, we compare our competition treatments to two monopoly treatments in which there is only one seller. In treatment NM (Name Your Own Price, Monopoly) a monopolistic seller is constrained to use the NYOP mechanism, in PM (Pay What You Want, Monopoly) he has to use the PWYW mechanism. These treatments are also interesting in their own right because in some markets in which customer-driven pricing mechanisms are used there is very little competition (e.g., museums, churches, etc.). The NM and PM treatment tell 
us how much customers are offering to pay under these mechanisms in the absence of any alternative suppliers.

At the beginning of each experiment instructions are read aloud. Then subjects have to answer a set of control questions to make sure that everybody understands the rules of the experiment. The experiment begins only after the answers have been checked by the experimenters. At the end of each experiment we elicit information about risk preferences and social preferences of the participants. For risk preferences we use a menu of ten paired lottery choices adapted from Holt and Laury (2002). For social preferences we rely on the six primary social value orientation (SVO) slider items of Murphy et al. (2011). The SVO measure consists of a series of allocation decisions that can be used to classify the social preferences of the decision maker. At the end of the experiment, one randomly selected decision of the Holt \& Laury-task and one randomly selected allocation decision from the SVO measure are paid out. We also ask subjects about their demographic characteristics.

In each treatment, subjects are randomly assigned to a role (i.e., buyer or seller) at the beginning of the experiment. This role remains fixed throughout the experiment. Each session consists of 24 subjects which gives us three markets in the competition treatments (two sellers facing six buyers in each market) and six markets in the monopoly treatments (one seller facing three buyers). All treatments are repeated for 20 periods, and subjects are randomly rematched every period. In the monopoly treatments we split each session into two matching groups. We conduct eight sessions of the competition treatments and another eight sessions of the monopoly treatments.

In order to perfectly control the valuations of the buyers and the cost of the sellers we use an induced-value design (Smith, 1976). A novel feature of our experimental design is a per-unit benefit $b \in\{0, \bar{b}\}$ that accrues to sellers using a customer-driven pricing mechanism. This benefit reflects a potential positive effect of using customer-driven pricing mechanisms because of the buzz and the word-of-mouth advertising it generates. Because these effects are increasing in the number of customers who actually buy the product under the customerdriven-pricing mechanism this benefit accrues to the seller in proportion to the units sold. However, the benefit is stochastic. A positive benefit $(b=\bar{b})$ accrues in only 50 percent of all markets, in the other 50 percent there is no benefit $(b=0)$. In the experiment buyers know the (constant) marginal cost of the sellers, but they do not know whether sellers enjoy a positive benefit from using a customer-driven pricing mechanism. This design choice reflects the idea that marginal costs can often be inferred from prices observed in the past, while 
most buyers are unaware of the fact that they generate a positive external effect on the seller by promoting his customer-driven pricing mechanism through word of mouth.

A total of 384 subjects participated in the experiment, 192 in the monopoly treatments and 192 in the competition treatments. Sessions lasted about two hours and subjects earned on average 18 Euros (about 24 US Dollars at the time of the experiment), including a show-up fee of 4 Euros ${ }^{12}$ All sessions were conducted at the experimental laboratory of the University of Munich (MELESSA). The subject pool consisted mainly of students from a wide range of majors. Treatments were implemented using zTree (Fischbacher, 2007) and subjects were recruited using ORSEE (Greiner, 2004).

In the following subsections we describe the treatments in more detail.

\subsection{Competition Treatments}

\subsubsection{Competition with Flexible Roles}

In treatments PCFlex and NCFlex one of the two sellers can choose whether to use posted prices or to use PWYW (NYOP, respectively) while the other (traditional) seller has to use a posted price. At the beginning of each period sellers and buyers observe the per-unit production cost of the good which is the same for both sellers and drawn from $c \in\{10,30,50\}$. The flexible seller privately learns the per-unit benefit $b \in\{0,40\}$ from using a customer-driven pricing mechanism and each buyer privately learns his valuation of the good which is drawn independently from $v \in\{10,25,40,60,120,200\}$. Then each seller decides whether to enter the market, and the flexible seller decides which pricing method to use. Then all buyers and sellers are informed about the market structure. Now the posted-price sellers set their prices, and a NYOP seller sets the threshold above which all price offers are accepted. Finally buyers decide whether and if so from which seller to buy. If they go for a posted-price seller they have to pay the posted price. If they go for a PWYW seller they get the good with certainty and can choose how much to pay for it voluntarily (including a price of zero). If they go for a NYOP seller they submit a bid. If the bid is greater than or equal to the secret threshold set by the seller, they pay their bid and receive the good. If the bid is smaller than the threshold, they do not receive the good and do not have to pay. Finally, payoffs are made.

\footnotetext{
${ }^{12}$ In all competition treatments, subjects received an additional payment for completing a survey at the end of the experiment. This payment was announced upon completion of the main experiment; therefore, we should not expect the decisions in the experiment to be distorted by income effects.
} 
Figure 1 summarizes the time and information structure of the competition treatments with flexible roles.

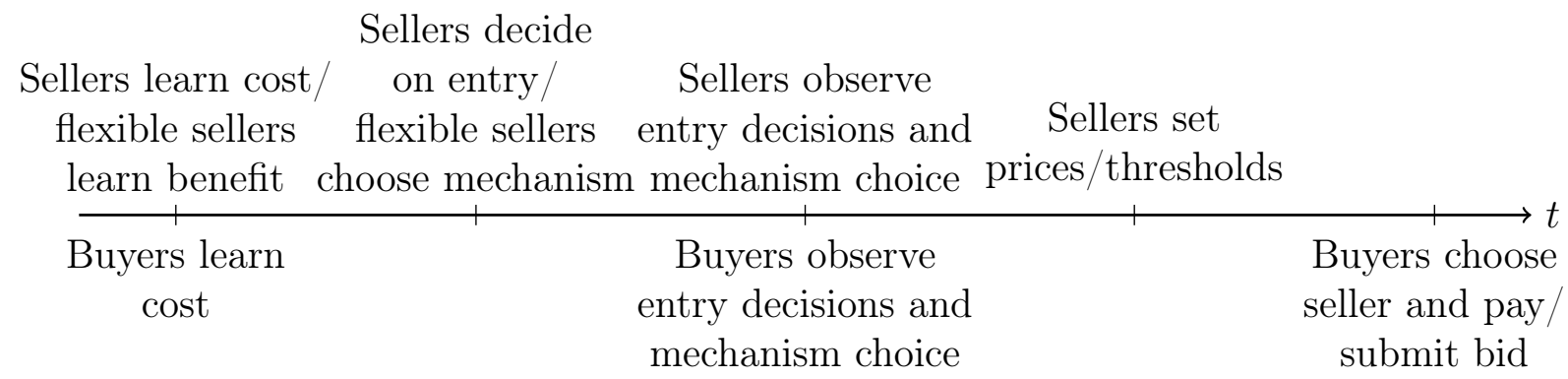

FIGURE 1.-Sequence of events in the flexible competition treatments.

A seller who stays out of the market gets a payoff of zero. If seller $j$ with cost $c$ quotes a posted price $p^{P}$ his payoff is given by

$$
\pi_{j}^{P}=\sum_{i=1}^{6} \mathbf{1}_{i}^{j}\left[p^{P}-c\right]
$$

where $\mathbf{1}_{i}^{j}$ is an indicator function equal to one if buyer $i$ decides to buy from seller $j$. If seller $j$ uses PWYW/NYOP his payoff is

$$
\pi_{j}^{P W Y W}=\pi_{j}^{N Y O P}=\sum_{i=1}^{6} \mathbf{1}_{i}^{j}\left[p_{i}-c+b\right]
$$

where $p_{i}$ refers to the price paid in PWYW and the submitted bid in NYOP, respectively, and $b$ is the per-unit benefit. Here, $\mathbf{1}_{i}^{j}$ is equal to one if buyer $i$ decides to buy from seller $j$ (and his submitted bid is greater than or equal to the threshold in the case of NYOP) and zero otherwise. The payoff of buyer $i$ is given by $v_{i}-p_{i}$ if a transaction takes place, and zero otherwise, where $v_{i}$ is his valuation and $p_{i}$ the price he paid.

\subsubsection{Competition Treatments with Fixed Roles}

The competition treatments with fixed roles (treatments PCFix and NCFix) are identical to the treatments with flexible roles except for the fact that one of the sellers has to use either PWYW or NYOP if he enters the market. 


\subsection{Monopoly Treatments}

In two monopoly treatments (PM and NM) there is only one seller who is forced to use PWYW (NYOP, respectively) if he enters the market. Here there are only three buyers in each market. Costs and benefits are parameterized as in the competition treatments, while buyers' valuations are drawn from a restricted set, $v=\{40,60,120,200\}$.13 All sellers have the same cost-benefit combination in a given period as in the competition treatments and learn that combination before market entry. The time structure of the monopoly treatments simplifies as depicted in Figure 2 .

$\begin{gathered}\text { Sellers (PWYW\&NYOP) } \\ \text { Sellers learn } \\ \text { decide on entry and set } \\ \text { thresholds (NYOP only) }\end{gathered}$
$\begin{gathered}\text { Buyers learn their } \\ \text { own valuation and } \\ \text { sellers' costs }\end{gathered}$

FIGURE 2.- Sequence of events for the monopoly treatments.

Seller $j$ 's payoff in these treatments is given by

$$
\pi_{j}= \begin{cases}\sum_{i=1}^{3} \mathbf{1}_{i}\left[p_{i}-c+b\right], & \text { if he entered the market } \\ 0, & \text { if he did not enter the market. }\end{cases}
$$

Again, $\mathbf{1}_{i}$ is an indicator function equal to one if buyer $i$ decides to buy (and his submitted bid is greater than or equal to the threshold in the case of NYOP) and zero otherwise. The buyers' payoffs are the same as in all other treatments.

\section{Theoretical Predictions}

As a benchmark for the experimental results we analyze the experimental treatments under the assumption that all buyers and sellers are fully rational and purely self-interested. To avoid uninteresting case distinctions we treat prices as continuous variables. Furthermore, we

\footnotetext{
${ }^{13}$ The competition treatments comprise a larger market and contain the additional valuations of 10 and 25. Therefore, profits cannot be directly compared between monopoly and competition treatments. However, in the monopoly treatments we are mainly interested in the behavior of buyers. For each given valuation of a buyer we can compare the behavior in the monopoly and the competition treatments.
} 
start out with the assumption that all subjects are risk neutral. The effects of risk aversion are discussed at the end of this section.

We solve the experimental games by backward induction. In the case of PWYW the analysis is straightforward:

Proposition 1. A purely self-interested buyer facing a PWYW seller pays $p=0$ and gets a strictly positive payoff $\pi_{i}=v_{i}-0>0$.

In all three PWYW treatments all buyers buy from the PWYW seller if this seller entered the market.

- In PCFix and PM the PWYW seller enters the market if and only if his benefit exceeds his cost, i.e., $b=40$ and $c \in\{10,30\}$. In this case he captures the entire market and makes a strictly positive profit while the PP seller makes a profit of zero. If the PWYW seller does not enter the PP seller charges monopoly prices.

- In PCFlex the flexible seller always enters the market and chooses PWYW if and only if his benefit exceeds his cost, i.e., $b=40$ and $c \in\{10,30\}$. In this case he captures the entire market and makes a strictly positive profit. If the flexible seller chooses to offer a posted price, both sellers engage in Bertrand competition and make zero profits.

Proposition 1 gives rise to the following very strong prediction:

Prediction 1. If PWYW is offered, then it captures the entire market, but all buyers pay a price of 0 . In all three PWYW treatments sellers use the PWYW pricing mechanism if and only if $b=40$ and $c \in\{10,30\}$.

These results suggest that the additional benefits generated by PWYW (e.g., via wordof-mouth effects) are the only reason to use this mechanism. However, these results are based on the assumption that all buyers are purely self-interested. If some buyers have social preferences and are motivated by fairness or reciprocity they may be willing to pay positive prices voluntarily. Furthermore, if a buyer feels obliged to make a positive payment under PWYW but does not want to engage in moral deliberations about how much to pay, he may prefer to buy from a posted-price seller, if such a seller is available.

Let us now turn to the NYOP treatments. In these treatments we ignore the entry decisions of the seller, because sellers could always guarantee non-negative profits if they 
entered. In fact almost all sellers choose to enter in the NYOP treatments 14 If a seller uses the NYOP mechanism he has to set a secret threshold $t$. A buyer gets the good if and only if the price he bids exceeds this threshold, i.e., $p \geq t$. The following lemma shows how a NYOP seller optimally sets this threshold:

Lemma 1. If a seller uses $N Y O P$ it is a (weakly) dominant strategy to set $t^{*}=\max \{c-b, 0\}$ in all treatments.

Proof. See Appendix A.1.

The intuition for this result is straightforward. Note first that the seller's "effective" marginal cost is $c-b$, and that he cannot set a threshold smaller than zero. Clearly, it cannot be optimal to set the threshold below marginal cost. Setting the threshold strictly above marginal cost cannot be optimal either, because the threshold is not observed by consumers and cannot affect their behavior. Thus, the only effect of a threshold greater than marginal cost is to reject some profitable price offers.

In the following we restrict attention to Perfect Bayesian equilibria in which a seller using the NYOP mechanism always chooses his (weakly) dominant strategy

Lemma 2. In the competition treatments a posted-price seller chooses $p^{P} \geq c$ and makes zero profits in equilibrium.

Proof. See Appendix A.1.

The intuition is again straightforward. Either both sellers use posted prices, in which case Bertrand competition drives prices down to marginal costs and profits to zero, or the flexible seller uses NYOP. Given his optimal threshold consumers can always get the good by bidding $b=c$. Thus, the posted-price seller may either set $p=c$ (in which case he may capture some market share) or $p>c$ in which case all consumers shop with the NYOP seller, but his profits are zero in any case.

\footnotetext{
${ }^{14}$ The fraction of sellers entering the market is above 98 percent in each of the three NYOP treatments.

${ }^{15}$ In the monopoly treatment this assumption is without loss of generality because $t=t^{*}$ is strictly optimal. In the duopoly treatments there are Perfect Bayesian equilibria in which the NYOP seller chooses a threshold $\bar{t}>c$, the posted-price seller offers $p^{P}$ such that $c \leq p^{P}<\bar{t}$ and all buyers with $v_{i}>p^{P}$ buy from the posted-price seller. These equilibria are sustained by the beliefs of the buyers that the NYOP seller sets the high threshold $\bar{t}>c$, so they never buy from this seller. Given that they do not buy, the thresthold $\bar{t}$ is (weakly) optimal. However, these equilibria are not trembling hand perfect. If there is an arbitrarily small probability that a buyer makes an offer to the NYOP seller, it is strictly optimal for the NYOP seller to set $t=t^{*}$.
} 
What is the optimal behavior of a risk neutral and self-interested buyer? The buyer rationally anticipates that the NYOP seller chooses threshold $t^{*}=\max \{c-b, 0\}$. In NCFix and NM the buyer does not know whether the actual benefit is $b=40$ or $b=0$, but he knows that each of these events occurs with equal probability.

Lemma 3. In treatments NCFix and NM a risk neutral buyer facing a NYOP seller offers

$$
p= \begin{cases}c & \text { if } v \geq \min \{2 c, c+40\} \\ \max \{c-40,0\} & \text { if } v<\min \{2 c, c+40\}\end{cases}
$$

Proof. See Appendix A.1.

The proof follows directly from Lemma 2 and the buyer's payoff function. Note that the buyer will bid aggressively only if his valuation is sufficiently small. Table 1 displays the optimal prices offered by a risk-neutral buyer to a NYOP seller as a function of the values that $v_{i}$ and $c$ could take in the experiment.

\begin{tabular}{llllllr}
\hline & \multicolumn{6}{c}{ Valuation } \\
Cost & 10 & 25 & 40 & 60 & 120 & 200 \\
\cline { 2 - 7 } 10 & $\mathbf{0}$ & 10 & 10 & 10 & 10 & 10 \\
30 & $\mathbf{0}$ & $\mathbf{0}$ & $\mathbf{0}$ & 30 & 30 & 30 \\
50 & $\mathbf{1 0}$ & $\mathbf{1 0}$ & $\mathbf{1 0}$ & $\mathbf{1 0}$ & 50 & 50 \\
\hline
\end{tabular}

TABle 1.- Optimal Bidding Behavior for Risk-Neutral EU Maximizers

Boldfaced values indicate cases in which a risk neutral buyer optimally submits an aggressive, "risky" bid to the NYOP seller that is strictly smaller than the seller's cost. In these cases it is strictly optimal for a risk neutral buyer to buy from the NYOP seller. If, on the other hand, a safe bid of $p=c$ is optimal, then the buyer may also buy from the posted-price seller, provided that this seller charges $p^{P}=c$.

In NCFlex the analysis is slightly more complicated. In this treatment the seller chooses whether to use NYOP after privately observing the realization of $b$. Thus, his choice may signal information about the realization of $b$ to the buyer. There exists a pooling equilibrium in which the flexible seller always uses NYOP and the buyer offers the prices given by Lemma 3 . However, there is also a separating equilibrium in which the seller uses NYOP if and only if $b=40$. Thus, if the buyers observe that NYOP is offered, they conclude in equilibrium that 
$b=40$ and offer $p=\max \{c-40,0\}$ for all realizations of $v$. This separating equilibrium is less profitable for the seller than the pooling equilibrium because prices and profits are lower, so sellers prefer the pooling equilibrium. Nevertheless, we cannot rule out the possibility that buyers interpret NYOP as a signal that $b=40$ and therefore bid more aggressively than they do in NCFix. But even in this case the NYOP seller makes strictly positive profits if $40-c>0$.

This analysis is summarized in the following prediction for the NYOP treatments:

\section{Prediction 2.}

1. In all three $N Y O P$ treatments a NYOP seller sets the optimal threshold $t^{*}=\max \{c-b, 0\}$. In the competition treatments a posted-price seller sets $p^{P} \geq c$ in equilibrium.

2. Buyers with a low valuation $(v<\min \{2 c, c+40\})$ buy from the NYOP seller and offer $p=\max \{c-40,0\}$ which is successful in 50 percent of all cases. Buyers with a higher valuation either buy from the NYOP seller and offer $p=c$ which is always successful, or they buy from the posted-price seller, but only if the posted-price seller offers $p^{P}=c$.

3. NYOP sellers make positive profits on average, while posted-price sellers always make zero profits in equilibrium. Furthermore, NYOP sellers always have a higher expected market share than posted-price sellers. If given a choice a seller prefers the NYOP mechanism over posted prices.

This prediction is based on several important assumptions. First, we assumed common knowledge of rationality and that buyers correctly anticipate the optimal threshold set by the NYOP seller. However, it is possible that some NYOP sellers fail to understand what the optimal threshold is and choose a threshold that is too high. Even if they choose the threshold optimally, buyers may believe that sellers behave irrationally with some probability. This may induce buyers to offer prices that are significantly higher than the optimal threshold. It may also induce buyers to buy from the posted-price seller where they can be sure to get the good with probability one. Finally, buyers may not be fully rational and have difficulties to compute the optimal threshold themselves. Again, this may induce them to offer a price that is higher than the seller's cost or to choose the posted-price seller.

Second, we assumed that buyers are risk neutral. If a buyer is risk averse, he may prefer a "safe" offer $p=c$ even if the expected profit of a "risky" offer $p=\max \{c-40,0\}$ is higher. 
Furthermore, if there is no common knowledge of rationality, risk aversion will exacerbate the effects of strategic uncertainty discussed above, i.e., the buyer may be inclined to offer even higher prices to the NYOP seller or lean more toward the posted-price seller where he can get the good with certainty.

Finally, we assumed that buyers are purely self-interested. If a buyer cares about the utility of the seller, he may offer higher prices to the NYOP seller in order to achieve a more equal income distribution.

\section{Results}

In this section we first analyze under what circumstances sellers choose to employ a customerdriven pricing mechanism and how successful these mechanisms are in penetrating the market and in making profits. Second, we analyze how buyers react to these mechanisms. Do they buy from a PWYW or NYOP seller or do they shy away from them? What prices do they pay? Do they behave differently if there is another posted-price seller as compared to a situation where the PWYW or NYOP seller is a monopolist? Third, we analyze the competitive effects of sellers employing PWYW and NYOP relative to a posted-price competitor.

\subsection{Seller's Choice and Performance of Customer-Driven Pricing Mechanisms}

We first consider the flexible competition treatments (PCFlex and NCFlex) in which sellers can choose which pricing mechanism to use. Under what conditions do sellers choose to delegate pricing power to their customers?

Result 1 (Seller's Choice of Customer-Driven Pricing Mechanism).

(a) In PCFlex almost all sellers choose to use PWYW if and only if PWYW offers an additional benefit and if production costs are not too high. If $P W Y W$ is chosen, then the PWYW seller captures almost all of the market and makes high profits.

(b) In NCFlex almost all sellers choose to use NYOP if NYOP offers an additional benefit. If there is no benefit still about half of the sellers choose NYOP if costs are not too high. If NYOP is chosen then the NYOP seller captures about 60 percent of the market. NYOP sellers choose a threshold close to the optimal threshold in 75 percent of all cases. 
(c) A flexible seller who chooses PWYW makes profits that are almost twice as high as the profits made by a flexible seller who chooses NYOP.

Support for Result 1 is provided by the descriptive statistics reported below. Table 2 reports the percentage of cases in which sellers opt for one of the customer-driven pricing mechanisms by cost and benefit levels. In both treatments all flexible sellers entered the market.

\begin{tabular}{lccccc}
\hline & \multicolumn{2}{c}{ PCFLEX } & & \multicolumn{2}{c}{ NCFLEX } \\
Cost & $b=0$ & $b=40$ & & $b=0$ & $b=40$ \\
\cline { 2 - 3 } \cline { 5 - 6 }$c=10$ & $6 \%$ & $100 \%$ & & $50 \%$ & $100 \%$ \\
$c=30$ & $0 \%$ & $100 \%$ & & $43 \%$ & $94 \%$ \\
$c=50$ & $0 \%$ & $13 \%$ & & $17 \%$ & $100 \%$ \\
\hline Total & $2 \%$ & $65 \%$ & $40 \%$ & $98 \%$ \\
\hline
\end{tabular}

TABLE 2.-Seller's Choice of Customer-Driven Pricing Mechanism

Note: Entries in cells denote the percentage of cases in which sellers opt for one of the customer-driven pricing mechanisms, conditional on entering the market.

In PCFlex almost all sellers shy away from PWYW if $b=0$. If there is a benefit and if $b>c$ all sellers choose PWYW, and 13 percent do so if $c=50$ and $b=40$. This result confirms Prediction 1. It seems that sellers are convinced that buyers are not going to make voluntary payments, so sellers avoid PWYW if this may result in losses. Note, however, that in the case where $c=50$ and $b=40$ there are twice as many sellers offering PWYW than if $c=10$ and $b=0$, even though these two cases are strategically equivalent. This suggests that sellers expect buyers to pay more if their costs are high than if their costs are low.

In NCFlex almost all flexible sellers choose NYOP if there is a positive benefit. If there is no benefit, still almost 50 percent of the sellers opt for NYOP if costs are 10 or 30, and 17 percent do so if costs are 50. This result is consistent with Prediction 2, Furthermore, it suggests that the choice of NYOP could be interpreted as a signal that the seller is more likely to enjoy a high benefit.

Using PWYW is highly profitable. The average profit of a PWYW seller is 127.1 points, as compared to an average profit of 58.1 of a seller using NYOP (see Table 3). However, because sellers could choose whether or not to employ the customer-driven pricing mechanism, these numbers have to be interpreted carefully. First of all, in PCFlex sellers opted for PWYW only if the benefit was high, while in NCFlex many sellers also chose NYOP when there was 
no benefit. But even if we restrict attention to the cases with $b=40$ and $c \in\{10,30\}$ where almost all flexible sellers opted for customer-driven pricing mechanism the average profit under PWYW is 145.1 while NYOP sellers make only 95.6 on average.

The reason why PWYW is more profitable than NYOP if benefits are higher than costs is the fact that PWYW is much more successful in market penetration. If the flexible seller chooses PWYW he gets a market share of 94.2 percent ${ }^{16}$ If the flexible seller chooses NYOP his market share is only 57.4 percent 17

\begin{tabular}{|c|c|c|c|c|}
\hline \multirow[b]{2}{*}{ Treatment } & \multicolumn{2}{|c|}{ Profits } & \multicolumn{2}{|c|}{ MARKET SHARES } \\
\hline & PWYW & NYOP & PWYW & NYOP \\
\hline Competition Flexible Roles & 127.1 & 58.1 & $94.2 \%$ & $57.4 \%$ \\
\hline Competition Fixed Roles & 76.8 & 69.7 & $90.0 \%$ & $69.8 \%$ \\
\hline Monopoly & 52.7 & 83.2 & $98.6 \%$ & $97.8 \%$ \\
\hline
\end{tabular}

TABlE 3.-Profits and Market Shares

Note: Profits and market shares are conditional on market entry and choice of the customer-driven pricing mechanism. Both profits and market shares are displayed as per period averages.

The overall picture of PWYW does not change much when we look at treatments PCFix and PM in which seller 1 had to use PWYW. Note that seller 1 could still decide not to enter the market. In fact, in PCFix the PWYW seller entered in only 51.7 percent of all cases (53.8 percent in PM). He stayed out of the market when there was no benefit $(b=0)$ and/or his cost was high $(c=50)$, so in the same situations in which he opted for posted prices in PCFlex. If he entered, he again captured almost the entire market (market share 90.0 percent). If $b=40$ and $c \in\{10,30\}$ the profits of the PWYW seller in PCFix are virtually identical to the profits in PCFlex. However, some PWYW sellers enter the market when $b=0$ in which case they make losses, so that the average profit conditional on market entry is lower, see Table 3. It is also interesting to note that profits are negative if $b=0$ and $c=10$, but positive if $b=40$ and $c=50$, even though these two situations are strategically equivalent. Thus, it must be the case that buyers voluntarily paid higher prices if the seller had higher costs. We will get back to this question below.

NYOP sellers' profits in NCFix are not significantly different from profits in NCFlex. Moreover, we find that buyers do not submit lower bids in NCFlex as compared to NCFix.

\footnotetext{
${ }^{16}$ The PP seller gets only 3.3 percent of the market, 2.5 percent of the buyers do not buy.

${ }^{17}$ The PP seller gets 35.5 percent of the market and 7.1 percent of the buyers do not buy.
} 
This indicates that the choice of NYOP does not provide an informative signal about the level of the benefit.

Did NYOP sellers set the thresholds optimally? By Proposition 1 it is a weakly dominant strategy to set $t=t^{*}=\max \{c-b, 0\}$. Across all treatments, 30.0 percent of the sellers choose exactly $t^{*}, 72.4$ percent choose a threshold within 10 points of $t^{*}$. There is no significant difference between treatments. On average the actually chosen threshold is 8.7 points higher than the optimal threshold, but this difference is decreasing over time suggesting that sellers learn to set the threshold optimally as they gain experience.18

\subsection{Buyers' Reactions to Customer-Driven Pricing Mechanisms}

How did buyers react if they were offered customer-driven pricing mechanisms? We first consider PWYW.

\subsubsection{Pay What You Want}

Result 2 (Voluntary Payments under PWYW).

(a) Buyers are not reluctant to buy from a PWYW seller.

(b) The majority of buyers (56.2 percent) pay positive prices and 26.2 percent pay prices greater than or equal to the seller's cost. On average each buyer pays 9.8 points, which is a significant contribution to sellers' profits.

(c) Buyers tend to pay more the higher their valuation and the higher the seller's cost. Payments are higher the higher the social value orientation (SVO) of a buyer. Buyers also pay more if there is no competing posted-price seller. Voluntary payments tend to decrease over time.

The high market share of more than 90 percent of PWYW sellers shows that buyers do not hesitate to buy from a PWYW seller. This result is in contrast to Schmidt et al. (2014) who find that a significant fraction of buyers prefer not buying from a PWYW seller, presumably because they are reluctant to engage in the moral deliberations of how much to pay. In the current study, almost all sellers who offered PWYW enjoy an additional benefit that

\footnotetext{
${ }^{18} \mathrm{~A}$ random-effects regression of the chosen threshold on the optimal threshold shows that $t^{*}$ explains the actually chosen threshold very well. The coefficient of $t^{*}$ is 0.9 . The treatment dummies and the interaction effects are not significant, but there is a significant negative time trend.
} 
makes PWYW profitable even if consumers do not pay positive prices. If buyers understand this, there is no reason to feel bad about accepting a PWYW offer. Thus, PWYW is a very effective instrument for market penetration.

Table 4 reports the average prices paid as well as the fractions of buyers paying positive prices and prices greater or equal than the seller's cost in all three PWYW treatments. These voluntary payments are a significant contribution to the sellers' profits under PWYW. This is not consistent with Proposition 1. Table 4 shows that social preferences do play an important role.

\begin{tabular}{lcccc}
\hline & Total & PCFlex & PCFix & PM \\
\hline Average price paid & 9.8 & 4.9 & 7.6 & 12.1 \\
Fraction of buyers paying $p>0$ & $56.2 \%$ & $38.1 \%$ & $50.4 \%$ & $64.1 \%$ \\
Fraction of buyers paying $p \geq c$ & $26.2 \%$ & $15.9 \%$ & $19.4 \%$ & $32.2 \%$ \\
\hline
\end{tabular}

TABLE 4.--Prices Paid under PWYW

Prices are lowest in PCFlex, higher in PCFix and highest in PM. A possible explanation is that in PCFlex sellers had the outside option to choose posted prices which they almost always did if $b=0$ and/or $c=50$. Thus, in PCFlex PWYW was profitable even if no positive prices were paid. In contrast, in PCFix and PM the outside option was to stay out of the market, so sellers chose PWYW more often, even in situations in which they could make losses. This may have induced buyers with social preferences to be more generous. Furthermore, in the monopoly treatment buyers had more reason to be grateful if the PWYW seller entered the market. In the monopoly treatment, if the buyer did not enter, they got a payoff of 0 . In the competition treatment they could still buy from the PP seller and get positive payoffs. This is a possible explanation for the higher payments observed in the monopoly treatment.

The regressions displayed in Table 5 show the driving forces of the behavior of buyers. Prices paid under PWYW are significantly increasing in the buyer's valuation and in the seller's cost. Thus, PWYW achieves endogenous price discrimination which is consistent with models of social preferences. The importance of social preferences is confirmed by the fact that SVO (social value orientation) also has a highly significant impact ${ }^{19}$ The price of the competing posted-price seller in the competition treatments has no significant effect. Note

\footnotetext{
${ }^{19}$ In PCFlex the seller's cost and the buyer's SVO are not significant. This could be related to the fact that a seller's mechanism choice signals to buyers that the benefit exceeds the marginal cost, and hence PWYW is profitable even if buyers pay a price of zero.
} 


\begin{tabular}{lccc}
\hline & $(1)$ & $(2)$ & $(3)$ \\
& $\begin{array}{c}\text { Price Paid } \\
\text { in PCFlex }\end{array}$ & $\begin{array}{c}\text { Price Paid } \\
\text { in PCFix }\end{array}$ & $\begin{array}{c}\text { Price Paid } \\
\text { in PM }\end{array}$ \\
\hline Cost & 0.058 & $0.212^{* * *}$ & $0.208^{* * *}$ \\
& $(0.094)$ & $(0.061)$ & $(0.037)$ \\
Valuation & $0.092^{* * *}$ & $0.117^{* * *}$ & $0.102^{* * *}$ \\
& $(0.015)$ & $(0.014)$ & $(0.009)$ \\
Posted Price of $S^{P}$ & -0.001 & -0.015 & \\
Period & $(0.026)$ & $(0.027)$ & \\
& $-0.586^{* * *}$ & $-0.650^{* * *}$ & $-0.359^{* * *}$ \\
SVO & $(0.206)$ & $(0.170)$ & $(0.112)$ \\
& 0.421 & $0.638^{* * *}$ & $0.606^{* * *}$ \\
Constant & $(0.317)$ & $(0.227)$ & $(0.133)$ \\
& $-19.701^{* *}$ & $-19.139^{* * *}$ & $-18.431^{* * *}$ \\
& $(8.512)$ & $(6.493)$ & $(3.848)$ \\
\hline Number of observations & 226 & 335 & 763 \\
\hline
\end{tabular}

TABle 5.-Prices Paid under PWYW

Note: Entries in columns (1)-(3) are point estimates from random-effects tobit regressions on buyers' prices paid to the PWYW seller (left-censored at minimum price of 0 ). ${ }^{*},{ }^{* *}$, *** denote significance at the $10 \%, 5 \%$, and $1 \%$ levels, respectively. Standard errors are in parentheses. 
that the variable "Period" has a significantly negative coefficient. This suggests that PWYW is more successful if it is newly introduced and if buyers did not yet get used to it.

\subsubsection{Name Your Own Price}

Result 3 (Bidding Behavior under NYOP).

(a) If NYOP is offered under competitive conditions about 60 percent of all buyers choose the NYOP seller.

(b) Buyers are more likely to choose NYOP the lower their valuation, the lower the seller's cost and the higher the posted price of the competing seller.

(c) Most buyers submit bids that are significantly higher than the optimal threshold of the seller. On average they are also significantly higher than the actual thresholds chosen by sellers. Bids tend to increase with the valuation of the buyer.

NYOP is significantly less successful in market penetration than PWYW (see Table 3). Table 6 reports average bid amounts and the fraction of successful bids in all three NYOP treatments. Bids are higher in the monopoly treatment than in the competition treatments.

\begin{tabular}{lcccc}
\hline & Total & NCFlex & NCFix & NM \\
\hline Average bid & 33.5 & 21.8 & 23.1 & 39.5 \\
Fraction of successful bids & $75.5 \%$ & $59.8 \%$ & $61.4 \%$ & $83.5 \%$ \\
\hline
\end{tabular}

TABLE 6.-Bids Submitted under NYOP

Regression (1) in Table 7 offers some insights into which buyers go for NYOP under which circumstances. The regression shows that buyers are less likely to choose a NYOP seller if their valuation is high and if the posted price of the competing seller is low. This is very intuitive. Given that not all NYOP sellers set the threshold optimally there is some strategic uncertainty whether a buyer gets the good under NYOP while he can be sure to get it if he pays the posted price of the competing seller. Thus, the higher his valuation (i.e., the more is at risk) and the lower the competing posted price the more is a buyer inclined not to buy from a NYOP seller. Surprisingly, our measure of risk aversion does not have a significant impact on buyers' choices. The buyers' social value orientation (SVO) is marginally significant (at the 10 percent level) suggesting that more socially minded buyers tend to use NYOP less 
often. The significant positive time trend suggests that buyers become less reluctant to use NYOP as they get more experienced.

\begin{tabular}{|c|c|c|c|c|}
\hline & $\begin{array}{c}(1) \\
\text { Choice of } \\
\text { NYOP seller }\end{array}$ & $\begin{array}{c}(2) \\
\text { Buyer's bid } \\
\text { in NCFlex }\end{array}$ & $\begin{array}{c}(3) \\
\text { Buyer's bid } \\
\text { in NCFix }\end{array}$ & $\begin{array}{c}(4) \\
\text { Buyer's bid } \\
\text { in NM }\end{array}$ \\
\hline Cost & $\begin{array}{c}-0.045^{* * *} \\
(0.008)\end{array}$ & & & \\
\hline Optimal Bid & & $\begin{array}{c}0.070 \\
(0.069)\end{array}$ & $\begin{array}{c}0.320^{* * *} \\
(0.056)\end{array}$ & $\begin{array}{c}0.686^{* * *} \\
(0.022)\end{array}$ \\
\hline Valuation & $\begin{array}{c}-0.022^{* * *} \\
(0.002)\end{array}$ & $\begin{array}{c}0.189^{* * *} \\
(0.019)\end{array}$ & $\begin{array}{c}0.186^{* * *} \\
(0.015)\end{array}$ & $\begin{array}{c}0.040^{* * *} \\
(0.006)\end{array}$ \\
\hline Posted Price of $S^{P}$ & $\begin{array}{c}0.068^{* * *} \\
(0.008)\end{array}$ & $\begin{array}{c}0.342^{* * *} \\
(0.041)\end{array}$ & $\begin{array}{c}0.093^{* * *} \\
(0.016)\end{array}$ & \\
\hline Risk Aversion & $\begin{array}{c}0.103 \\
(0.070)\end{array}$ & $\begin{array}{c}0.032 \\
(0.284)\end{array}$ & $\begin{array}{c}0.456 \\
(0.437)\end{array}$ & $\begin{array}{l}-0.135 \\
(0.369)\end{array}$ \\
\hline SVO & $\begin{array}{l}-0.019^{*} \\
(0.011)\end{array}$ & $\begin{array}{c}0.066 \\
(0.050)\end{array}$ & $\begin{array}{c}0.080 \\
(0.056)\end{array}$ & $\begin{array}{c}0.001 \\
(0.048)\end{array}$ \\
\hline Period & $\begin{array}{c}0.061^{* * *} \\
(0.015)\end{array}$ & $\begin{array}{c}0.130 \\
(0.094)\end{array}$ & $\begin{array}{l}-0.111 \\
(0.084)\end{array}$ & $\begin{array}{c}-0.206^{* * *} \\
(0.053)\end{array}$ \\
\hline Constant & $\begin{array}{l}-0.489 \\
(0.602)\end{array}$ & $\begin{array}{l}-3.670 \\
(2.922)\end{array}$ & $\begin{array}{c}2.964 \\
(3.700)\end{array}$ & $\begin{array}{c}23.686^{* * *} \\
(2.250)\end{array}$ \\
\hline Number of observations & 1175 & 286 & 489 & 1409 \\
\hline
\end{tabular}

TABLE 7.-Buyers' Behavior if NYOP Is Chosen.

Note: Entries in column (1) are point estimates from a random-effects logistic regression on buyers' choice of seller in treatments NCFlex and NCFix. The dependent variable is 1 if the buyer opted for the NYOP seller and 0 otherwise. Entries in columns (2)-(4) are point estimates from random-effects tobit regressions on buyers' submitted bids to the NYOP seller (left-censored at minimum bid of 0 ). ${ }^{*},{ }^{* *},{ }^{* * *}$ denote significance at the $10 \%, 5 \%$, and $1 \%$ levels, respectively. Standard errors are in parentheses.

Regressions (2) to (4) in Table 7 show the driving forces of the bids submitted if a buyer chooses the NYOP seller. The theoretically optimal bid derived under the assumption of common knowledge of rationality and risk neutrality in Table 1 is highly significant in the NCFix and NM treatments. According to Prediction 2 the coefficients of "Optimal Bid" should be equal to 1 , but they are not even close ${ }^{20}$ The buyer's valuation also has a highly significant

\footnotetext{
${ }^{20}$ The parameter estimates for Optimal Bid are significantly different from 1 in NCFlex $\left(\chi^{2}(1)=181.99, p<\right.$ $0.001)$, NCFix $\left(\chi^{2}(1)=149.11, p<0.001\right)$, and NM $\left(\chi^{2}(1)=200.57, p<0.001\right)$.
} 
positive effect as does the posted price of the competing seller. Again, this is very intuitive. Given that many sellers choose thresholds that are too high, buyers cannot be sure to get the good if they submit the theoretically optimal bid. Thus they will bid higher the more is at stake and the less attractive it is to switch to the posted-price seller. We do not find a significant effect of our measure of risk aversion and of SVO. There is a significant negative time trend suggesting that buyers bid more aggressively as they gain more experience in NM.

\subsection{Customer-Driven Pricing Mechanisms as a Competitive Strat- egy}

How do customer-driven pricing mechanisms affect competition? Figure 3 compares profits of the seller using PWYW or NYOP to the profits of his posted-price competitor. In Section 4.1 we have already seen that if PWYW is used it is highly profitable and captures almost the entire market. Thus, not surprisingly, the profits of the competing posted-price seller are very close to zero. If, on the other hand, the flexible seller also chooses posted prices, then both sellers share the market equally and make a small (combined) profit of 8.2. ${ }^{21}$ Thus, the competing PP seller suffers if the flexible seller chooses PWYW.

Perhaps surprisingly this is not the case with NYOP. Profits of the PP seller are unaffected if the flexible seller opts for NYOP, while profits of the flexible seller go up significantly. This suggests that NYOP relaxes competition. In fact the markup charged by a PP seller competing against a NYOP seller in the two competition treatments is 18.8, which is significantly higher than the markup of 7.8 charged by PP sellers against a flexible seller who has chosen to use a posted price in NCFlex. The reason why NYOP relaxes price competition is that the NYOP seller does not quote a price. Furthermore, because NYOP is most attractive to low valuation customers, PP sellers can focus on high valuation customers and charge them a higher price. This is summarized in our last result.

Result 4 (The Effects on Competition). $P W Y W$ is an aggressive competitive strategy driving a competing posted-price seller out of the market. This is not the case for NYOP. NYOP leaves room for competing sellers and it relaxes price competition. Sellers may be better off if one of them uses $N Y O P$.

\footnotetext{
${ }^{21}$ This is higher than the theoretically predicted profit of zero. However, many other experiments have already shown that sellers set prices somewhat above marginal costs even if they are engaged in Bertrand competition. See, e.g., Dufwenberg and Gneezy (2000).
} 

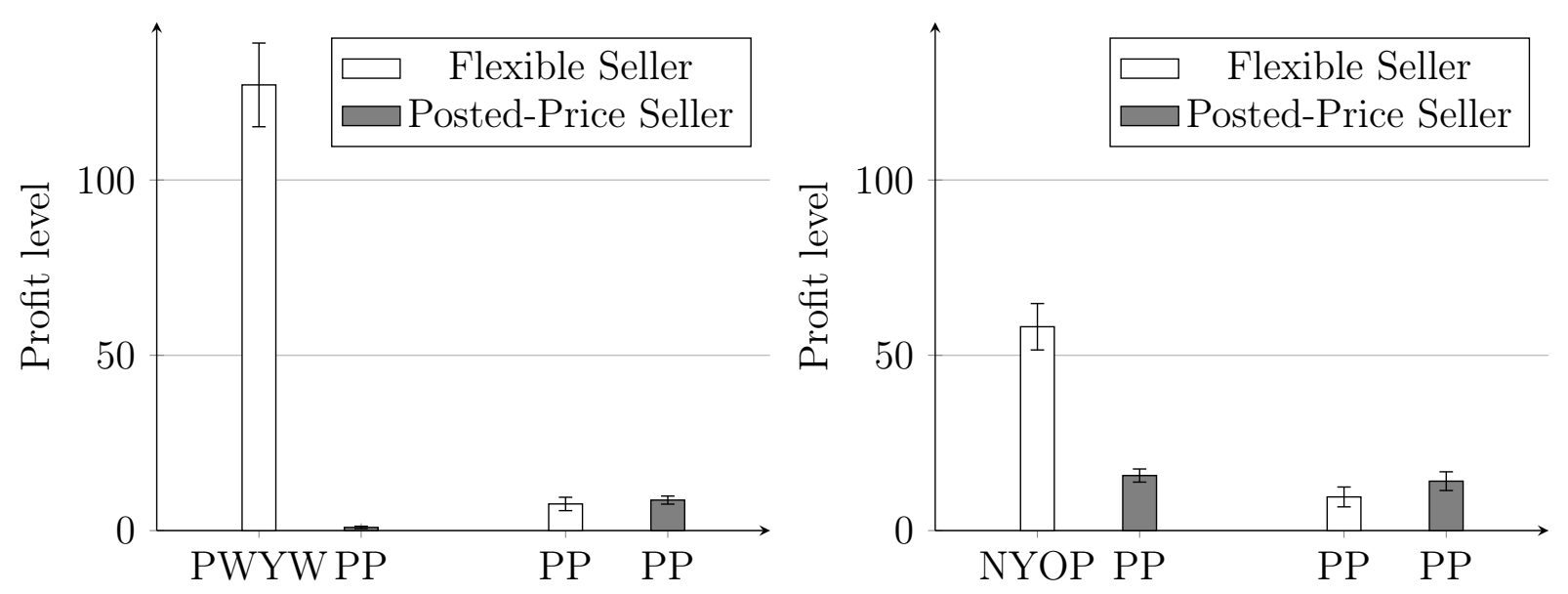

FIGURE 3.-The Effects on Competition

Note: The left panel shows profit levels in PCFlex for the two different competitive environments. The two left-most bars indicate competition between a PWYW and a PP seller, while the bars on the right depict competition between two posted-price sellers. Profit levels for the NCFlex treatment are depicted analogously in the right panel. Throughout, the error bars show standard errors of the mean.

It is important to note that additional benefits are an important precondition for most PWYW sellers to enter the market in a competitive situation. However, if this is the case, then a PWYW seller captures most of the market compared to a posted-price competitor. This is different for a NYOP seller. NYOP can be profitable even if there is no additional benefit and if costs are high. Furthermore, a NYOP seller captures only about 60 to 70 percent of the market, leaving (mostly high valuation) customers for a posted-price competitor. High valuation customers shy away from the risk of not getting the good associated with bidding under NYOP.

\section{Conclusions}

Customer-driven pricing mechanisms are widely and increasingly used, but we do not yet fully understand under which conditions they can be successfully applied and what factors determine their viability. The present paper uses a laboratory experiment to answer some of the open questions. There are clearly many differences between a laboratory experiment and a real world market, and we have to be careful how to interpret our results. However, the main advantage of laboratory experiments are the tightly controlled environment and the exogenous randomization that allow us to make causal inferences about the effects of 
buyer and seller characteristics and the competitive environment on important managerial outcome measures such as profits, market penetration and endogenous price discrimination. Furthermore, it allows us to directly compare the performance of PWYW and NYOP under identical conditions. Of course, the quantitative effects observed in the lab cannot be directly transferred to any real world markets. But the qualitative effects observed in the lab are likely to play a role in the real world as well and allow us to draw some important lessons on customer-driven pricing mechanisms.

Our analysis shows that PWYW and NYOP are effective methods of endogenous price discrimination. Both of these marketing strategies delegate (some) pricing power to buyers, and both strategies avoid setting a reference price. Both strategies can be profitable in large anonymous markets in which customers shop only once and have no interest in keeping the firm in business. However, despite these similarities the two pricing strategies work very differently and should be used under different circumstances.

PWYW achieves price discrimination by appealing to social preferences. There is a significant fraction of the population that is willing to voluntarily pay positive prices, which generates significant revenues. Prices paid increase with the consumer's valuation, with his prosociality, and with the seller's cost. However, these revenues alone are often not sufficient to cover costs. Thus, PWYW is particularly interesting if it generates an additional marketing benefit (such as increased press coverage or word-of-mouth recommendations) and if marginal costs are small. In these cases PWYW can be highly profitable because it achieves (almost) full market penetration. It is also a very aggressive strategy driving other posted-price sellers out of the market.

NYOP price discriminates by creating strategic uncertainty. Low valuation buyers find NYOP very attractive because it offers a chance to get the good at a lower price. High valuation buyers prefer a posted-price seller, because they do not want to take the risk of not getting the good if their bid is below the seller's reserve price. Thus, NYOP can be employed to access new customer segments that did not buy the good beforehand while most existing (high valuation) customers still buy at the posted price. Notably, social preferences do not affect how much consumers bid. NYOP has the advantage that the seller can protect himself against losses by setting an appropriate reserve price. Therefore, NYOP can also be used profitably if there is no additional benefit and if marginal costs are high. The drawback of NYOP is that it is less successful in penetrating the market and leaves room for additional posted-price sellers. In fact, NYOP is a strategy that relaxes price competition and increases 
total industry profits.

From a managerial perspective, PWYW is most likely to be successful if capacity constraints are negligible, marginal costs are low and/or the seller profits from additional promotional benefits. Anecdotal evidence corresponds to this observation: for instance, hotels use PWYW as a short-term instrument to attract additional customers and increase capacity utilization. In a similar vein, restaurants can accomodate fluctuations in demand by offering PWYW only during lunchtime, while resorting to posted prices in busy periods. Finally, the conditions for successfully employing PWYW are often favorable in digital goods and service industries.

The downside of achieving (almost) full market penetration is that PWYW cannot be used as an additional sales channel simultaneously with a posted price. NYOP, on the other hand, can be employed as a complementary way to sell excess capacity via third-party intermediaries on a permanent basis. It successfully segments the market into high-valuation customers who are more inclined to buy at posted prices and low-valuation customers who would not have been served in a market with two traditional posted-price sellers. NYOP can therefore be employed parallel to posted prices in order to access new customer segments. 


\section{A Appendix}

\section{A.1 Proofs}

Proof of Lemma 1. Because the threshold is set secretly it cannot affect the behavior of the buyers nor of a competing seller. Note that the threshold has to be nonnegative. Suppose that the seller sets a threshold $\hat{t}>t^{*}$. Buyers offering a price $p \geq \hat{t}$ receive the good and pay the offered price under both $\hat{t}$ and $t^{*}$. Buyers offering a price $p<t^{*}$ do not receive the good and do not pay anything under both thresholds. Thus, in these cases the threshold does not make a difference. However, if a buyer offers a price $p$ such that $t^{*} \leq p<\hat{t}$, then the buyer does not get the good under threshold $\hat{t}$ and the seller makes zero profit, while the buyer gets the good under threshold $t^{*}$ and the seller makes a positive profit of $p-c+b>0$ from this customer. Thus, the seller is better off with threshold $t^{*}$ than with threshold $\hat{t}>t^{*}$. Similarly, suppose that the seller sets a threshold $\hat{t}<t^{*}$. Again, if $p<\hat{t}$ or if $p \geq t^{*}$ it does not make a difference whether the threshold is $\hat{t}$ or $t^{*}$. However, if $\hat{t} \leq p<t^{*}$ then the buyer gets the good under threshold $\hat{t}$ yielding a negative profit of $p-c+b<0$ for the seller, while the buyer does not get the good and the seller's profit is zero under threshold $t^{*}$. Thus, setting $t^{*}=\max \{c-b, 0\}$ is indeed a (weakly) dominant strategy.

Proof of Lemma 2. Two cases have to be distinguished. (1) If both sellers are posted-price sellers (which may happen in the flexible competition treatment) the unique (Bertrand) equilibrium of the this game is that both posted-price sellers charge $p^{P}=c$. (2) If a postedprice seller faces a NYOP seller the NYOP seller sets the threshold $t^{*}=\max \{c-b, 0\}$ and all buyers buy from him if $p^{P}>c$. In this case the posted-price seller makes a profit of zero. If he sets $p^{P}=c$ some buyers may buy from him, but his profit is again zero. Charging $p^{P}<c$ can only yield losses and is dominated by $p^{P}=c$.

Proof of Lemma 3. If the buyer makes an offer to the NYOP seller he should either offer $p=c$ which gets him the good with certainty or $p=\max \{c-40,0\}$ which is successful with probability 0.5 . The safe bid is optimal if $v_{i}-c \geq \frac{1}{2}\left[v_{i}-\max \{c-40,0\}\right]$, which is equivalent to $v_{i} \geq \min \{2 c, c+40\}$. 


\section{A.2 Experimental Instructions (for Online Publication)}

The following instructions were presented to subjects in the NCFix treatment. All other instructions were adapted accordingly and are available from the authors upon request. Instructions were succeeded by a set of control questions (not shown here) that were checked by the experimenters after the subjects had answered them in private.

\section{Welcome to the Experiment and Thank You fo Participating!}

From now on, please do not talk to any of the other participants of the experiment.

\section{General Information}

The purpose of this experiment is to study economic decision behavior. By participating, you can earn money. Following the experiment, you will be paid out in cash.

During the experiment, you and the other participants will be asked to make decisions. Both your own decisions and those of the other participants determine your payoff according to the rules explained below.

The whole experiment will take about two hours. In the beginning you will receive detailed instructions. If you have any questions after the instructions or during the experiment, please raise your hand. One of the supervisors of the experiment will come to your cubicle and privately answer your questions. The question will be repeated and answered publicly if it is relevant for all participants. You will have to answer some control questions after the instructions before we can start the experiment.

For linguistic convenience we use male terms throughout.

\section{Payment}

We will talk about points and not Euro in the experiment. These points will be converted into Euro at the end of the experiment. The exchange rate is:

\section{0 points $=1$ Euro}

In addition, you will receive an initial endowment of 480 points ( 4 Euro) at the beginning of the experiment. There will be an additional compensation for filling out a questionnaire at the end of the experiment. 


\section{Anonymity}

Your decisions and payoffs are anonymous: Neither will you receive any information concerning the decisions or payoffs of the other participants, nor will the other participants receive any information concerning your own decisions or payoffs. We will analyze the collected data anonymously and will never link names to data from the experiment. At the end of the experiment you will have to sign a receipt stating that you received your payment. This receipt is used for accounting purposes only.

\section{Miscellaneous}

There will be a pen on your desk. Please leave this pen on the table after the experiment.

\section{The Experiment}

\section{Roles}

There are two roles in the experiment, which we will refer to as buyer and seller in the following. Your role will be assigned to you randomly and will stay the same for the duration of the experiment.

\section{Decisions and Procedures}

The experiment consists of 20 periods. In all periods the same kind of decisions will have to be made.

At the beginning of each period, two sellers will be matched with six randomly selected buyers. Each buyer is assigned to exactly two sellers: one of them will be a posted-price seller and the other will be a Name Your Own Price seller. Buyers can purchase exactly one unit of the offered good in each period if at least one seller has entered the market. Buyers can thus decide from which seller he wants to buy or if he does not want to buy at all.

How do the two sellers differ?

- If the posted-price seller offers his good, he sells it through the posted-price mechanism. This means that the seller chooses a price for which buyers can purchase the good. If a buyer decides to buy the good, he pays the posted price. If he does not buy the good, there will be no trade and both the buyer and the seller will receive a payoff of 0 points. 
- If the Name Your Own Price seller offers his good, he sells it through the Name Your Own Price mechanism. This means that, in a first stage, the seller determines a price threshold that is known only to him. Each buyer will then decide on his own which price he wants to offer for the good. The seller has to deliver the good only if the buyer has offered a price greater than or equal to the price threshold (which is still unknown to the buyer). If the price is greater than or equal to the price threshold, the buyer will pay exactly the amount he offered; if the price is lower than the price threshold, there will be no trade and both buyer and seller will receive a payoff of $\mathbf{0}$ points.

Each period consists of 5 stages:

1. In the first stage of each period, sellers are told their costs for producing a unit. These costs are the same for both sellers. Moreover, the Name Your Own Price seller learns about the benefit that he will receive every time he sells a good. Only the Name Your Own Price seller can receive this benefit; the posted-price seller neither knows about the size of the benefit nor will he receive it.

2. In the second stage of each period, sellers will independently decide whether to offer the good or not. If a seller does not enter the market, he will receive a payoff of $\mathbf{0}$ points; in that case, buyers still have the chance to buy the good from the remaining seller. If none of the sellers enter the market, both sellers and their assigned buyers will get a payoff of $\mathbf{0}$ points and the period ends.

3. In the third stage of each period, sellers are informed whether the other seller has entered the market or not.

4. If the posted-price seller has entered the market, he determines the price at which the good is available to buyers in stage four of the period. If the Name Your Own Price seller has entered the market, he must specify a price threshold. Only offers that exceed this threshold will lead to a transaction.

5. In the fifth stage, buyers learn their valuation for the good. This translates to the payment a buyer will receive at the end of the experiment if he has bought the good. In addition, buyers will be informed about sellers' costs of production for the good. Each buyer now decides whether to buy the good and if he wants to buy it, where to buy it. 
If he decides to buy from the Name Your Own Price seller, he also has to make an offer for the good.

After each period, two sellers (one posted-price seller and one Name Your Own Price seller) will be assigned anew to six randomly selected buyers.

\section{Detailed Procedures}

Each period proceeds as follows:

1. Sellers are informed about their costs of production for each sold unit of the good. Costs can be 10, $\mathbf{3 0}$ or $\mathbf{5 0}$ points and are randomly drawn in each period. Moreover, the Name Your Own Price seller receives a benefit for each unit sold. The Name Your Own Price seller learns whether the benefit is $\mathbf{0}$ or $\mathbf{4 0}$ points.

2. Sellers decide independently from each other whether to offer the good in this period or not. If a seller does not enter the market, he receives a payoff of $\mathbf{0}$ points. In this case, buyers have the opportunity to purchase the good from the remaining seller. If none of the sellers enter the market, both of them and their assigned buyers get a payoff of $\mathbf{0}$ points and the period ends.

3. Sellers are informed whether the respective other seller has entered the market or not.

4. If the posted-price seller has entered the market, he must now determine a price. This price is identical for all buyers on the market and can vary between 0 and 200 points.

If the Name Your Own Price seller has entered the market, he must determine the threshold price. This threshold price is also identical for all buyers on the market. All integers between 0 to 200 points are valid thresholds.

5. Buyers are informed about their valuation for the good. This valuation can be $\mathbf{1 0}, \mathbf{2 5}$, $40,60,120$ or 200 points and is drawn randomly in each period. It is possible that multiple buyers have the same valuation. In addition, buyers are informed about the unit costs of sellers.

Subsequently, all buyers decide whether to buy the good and if yes, where to buy it. If the buyer chooses the Name Your Own Price seller, he also needs to decide which price he would like to offer for the good. The mount of this offer can be freely chosen. Each amount between 0 points and the own valuation in points is valid. 
6. Buyers learn their income that they have earned in the current period. Buyers who opted for the Name Your Own Price seller are informed whether their offer was successful or not.

Posted-price sellers learn how many buyers bought at the posted price, how many buyers submitted an offer to the Name Your Own Price seller and how much they earned.

Name Your Own Price sellers learn the prices offers submitted by each of their buyers and whether these offers were successful. In addition, Name Your Own Price sellers are informed about the number of buyers who decided to buy from the posted-price seller and learn their payoff in the current period.

\section{End of a Period}

At the end of each period, sellers and buyers are separated and two sellers (one posted-price seller and one Name Your Own Price seller) are assigned to six new, randomly selected, buyers. Hence, a market always consists of one posted-price seller, one Name Your Own Price seller and six buyers. After 20 periods the experiment ends.

\section{Calculation of Income at the End of each Period}

If none of the sellers have entered the market in a given period, both sellers and the respective six buyers in the market receive $\mathbf{0}$ points.

\section{Buyers}

Buyers can either buy from the posted-price seller, or from the Name Your Own Price seller, or they can choose not to buy at all.

\section{Transacting with the Posted-Price Seller}

If a buyer purchases from the posted-price seller, his income equals his valuation $V$ minus the posted price $P_{P}$.

$$
\text { Income }=\text { Valuation }(V)-\text { Posted Price }\left(P_{P}\right)
$$




\section{Transacting with the Name Your Own Price Seller}

If a buyer purchases from the Name Your Own Price seller and if his offer was successful, his income equals his valuation $(V)$ minus the offered price $\left(P_{O}\right)$.

$$
\text { Income }=\text { Valuation }(V)-\text { Offered Price }\left(P_{O}\right)
$$

\section{No Transaction}

If the buyer does not trade in this period, which can happen when

- None of the sellers have entered the market, or

- The buyer did not buy the good either from the posted-price seller or from the Name Your Own Price seller, or

- The price offer of the buyer was not greater than or equal to the price threshold of the Name Your Own Price seller and was therefore not successful,

the income of the buyer equals $\mathbf{0}$ points.

\section{Posted-Price Seller}

The income of the posted-price seller equals his revenues minus his costs.

- His revenue is calculated by multiplying the posted price he determined with the number of goods sold.

- His costs are calculated by multiplying the unit cost $(C)$ with the number of goods sold. Thus, if the seller has entered the market and three buyers have purchased from him:

$$
\begin{aligned}
\text { Income }= & \text { Sum of Posted Prices }\left(3 \cdot P_{P}\right) \\
& - \text { Sum of Unit Costs }(3 \cdot C)
\end{aligned}
$$

If the posted-price seller has not entered the market, his revenue in this particular period equals $\mathbf{0}$ points.

If a buyer does not buy the good from him, there will be no unit costs for this buyer and the seller will not receive any money from this buyer. 


\section{Name Your Own Price Seller}

The income of the Name Your Own Price seller is his revenue plus the benefit and minus his costs.

- His revenue is the sum of the offered prices that are greater than or equal to his price threshold, plus the benefit $(B)$ multiplied with the number of goods sold.

- His costs are the unit costs $(C)$ multiplied with the number of goods sold.

Thus, if the seller has entered the market and the price offers of three buyers are successful:

$$
\begin{aligned}
\text { Income }= & \text { Sum of Offered Prices } \\
& \left(P_{O}^{1}+P_{O}^{2}+P_{O}^{3}\right) \\
+ & \text { Sum of Unit Benefits }(3 \cdot B) \\
- & \text { Sum of Unit Costs }(3 \cdot C)
\end{aligned}
$$

If the Name Your Own Price seller has not entered the market, his revenue for this particular period equals $\mathbf{0}$ points.

If a buyer's offered price is below the price threshold, there are no unit costs and no benefits and he will not receive a price from this buyer.

If a seller or a buyer incurs a loss in any given period, they have to use their previous profits or their initial endowment, respectively, to compensate for this loss.

Do you have any questions up to this point? 


\section{References}

Abbas, A. E. and Hann (2010). Measuring risk aversion in a name-your-own-price channel. Decision Analysis, 7(1):123-136.

Amaldoss, W. and Jain, S. (2008). Joint bidding in the name-your-own-price channel: A strategic analysis. Management Science, 54(10):1685-1699.

Anderson, C. K. (2009). Setting prices on priceline. Interfaces, 39(4):307-315.

Chernev, A. (2003). Reverse pricing and online price elicitation strategies in consumer choice. Journal of Consumer Psychology, 13(1/2):51-62.

Ding, M., Eliashberg, J., Huber, J., and Saini, R. (2005). Emotional bidders - an analytical and experimental examination of consumers' behavior in a priceline-like reverse auction. Management Science, 51(3):352-364.

Dolan, R. J. and Moon, Y. (2000). Pricing and market making on the internet. Journal of Interactive Marketing, 14(2):56-73.

Dufwenberg, M. and Gneezy, U. (2000). Price competition and market concentration: An experimental study. International Journal of Industrial Organization, 18(1):7-22.

Fay, S. (2004). Partial-repeat-bidding in the name-your-own-price channel. Marketing Science, $23(3): 407-418$.

Fay, S. (2009). Competitive reasons for the name-your-own-price channel. Marketing Letters, 20(3):277-293.

Fay, S. and Laran, J. (2009). Implications of expected changes in the seller's price in name-your-own-price auctions. Management Science, 55(11):1783-1796.

Fay, S. and Lee, S. H. S. (2015). The role of customer expectations in name-your-own-price markets. Journal of Business Research, 68(3):675-683.

Fischbacher, U. (2007). z-tree: Zurich toolbox for ready-made economic experiments. Experimental Economics, 10(2):171-178.

Gautier, P. A. and van der Klaauw, B. (2012). Selection in a field experiment with voluntary participation. Journal of Applied Econometrics, 27(1):63-84. 
Gneezy, A., Gneezy, U., Nelson, L. D., and Brown, A. (2010). Shared social responsibility: A field experiment in pay-what-you-want pricing and charitable giving. Science, 329(5989):325327.

Greiner, B. (2004). An online recruitment system for economic experiments. In Kremer, K. and Macho, V., editors, Forschung und wissenschaftliches Rechnen 2003, volume GWDG Bericht 63, pages 79-93. Gesellschaft für Wissenschaftliche Datenverarbeitung, Göttingen.

Hann, I.-H. and Terwiesch, C. (2003). Measuring the frictional costs of online transactions: The case of a name-your-own-price channel. Management Science, 49(11):1563-1579.

Hinz, O., Hann, I.-H., and Spann, M. (2011). Price discrimination in e-commerce? An examination of dynamic pricing in name-your-own price markets. MIS Quarterly, 35(1):8198.

Hinz, O. and Spann, M. (2008). The impact of information diffusion on bidding behavior in secret reserve price auctions. Information Systems Research, 19(3):351-368.

Holt, C. A. and Laury, S. K. (2002). Risk aversion and incentive effects. American Economic Review, 92(5):1644-1655.

Johnson, J. W. and Cui, A. P. (2013). To influence or not to influence: External reference price strategies in pay-what-you-want pricing. Journal of Business Research, 66(2):275-281.

Kalyanaram, G. and Winer, R. S. (1995). Empirical generalizations from reference price research. Marketing Science, 14(3):161-169.

Kim, J.-Y., Natter, M., and Spann, M. (2009). Pay what you want: A new participative pricing mechanism. Journal of Marketing, 73(1):44-58.

Kim, J.-Y., Natter, M., and Spann, M. (2010). Kish: Where customers pay as they wish. Review of Marketing Science, 8(2):Article 3.

León, F. J., Noguera, J. A., and Tena-Sánchez, J. (2012). How much would you like to pay? Trust, reciprocity and prosocial motivations in el trato. Social Science Information, $51(3): 389-417$. 
Mak, V., Zwick, R., and Rao, A. R. (2015). "Pay what you want" as a profitable pricing strategy: Theory and experimental evidence. Organizational Behavior and Human Decision Processes, 127:30-34.

Murphy, R. O., Ackermann, K. A., and Handgraaf, M. J. J. (2011). Measuring social value orientation. Judgment and Decision Making, 6(8):771-781.

Regner, T. (2014). Social preferences? Google answers! Games and Economic Behavior, 85:188-209.

Regner, T. and Barria, J. A. (2009). Do consumers pay voluntarily? The case of online music. Journal of Economic Behavior \&6 Organization, 71(2):395-406.

Schmidt, K. M., Spann, M., and Zeithammer, R. (2014). Pay what you want as a marketing strategy in monopolistic and competitive markets. Management Science.

Shapiro, D. (2011). Profitability of the name-your-own-price channel in the case of risk-averse buyers. Marketing Science, 30(2):290-304.

Smith, V. L. (1976). Experimental economics: Induced value theory. American Economic Review, 66(2):274-279.

Spann, M., Häubl, G., Skiera, B., and Bernhardt, M. (2012). Bid-elicitation interfaces and bidding behavior in retail interactive pricing. Journal of Retailing, 88(1):131-144.

Spann, M., Skiera, B., and Schäfers, B. (2004). Measuring individual frictional costs and willingness-to-pay via name-your-own-price mechanisms. Journal of Interactive Marketing, $18(4): 22-36$.

Spann, M. and Tellis, G. J. (2006). Does the internet promote better consumer decisions? The case of name-your-own-price auctions. Journal of Marketing, 70(1):65-78.

Spann, M., Zeithammer, R., and Häubl, G. (2010). Optimal reverse-pricing mechanisms. Marketing Science, 29(6):1058-1070.

Terwiesch, C., Savin, S., and Hann, I.-H. (2005). Online haggling at a name-your-own-price retailer: Theory and application. Management Science, 51(3):339-351. 
Wang, T., Gal-Or, E., and Chatterjee, R. (2009). The name-your-own-price channel in the travel industry: An analytical exploration. Management Science, 55(6):968-979.

Weatherford, L. R. and Bodily, S. E. (1992). A taxonomy and research overview of perishableasset revenue management: Yield management, overbooking, and pricing. Operations Research, 40(5):831-844. 